\title{
DIFERENÇAS ENTRE SISTEMAS GERENCIAIS DE EMPREENDEDORES E OPERADORES DE PEQUENOS NEGÓCIOS
}

Mestre em Relações Internacionais pela Universidade de Ottawa, MBA pela HEC (the University of Montreal Business School), Ph.D. em Entrepreneurship pela Universidade de Lancaster e Professor responsável pela cadeira de Entrepreneurship Maclean Hunter da HEC.

\section{RESUMO}

A partir de um estudo empírico sobre o sistema gerencial de 116 gerentesproprietários de pequenos negócios, eles foram divididos em dois grupos. Um total de 74 foi classificado como empreendedores, e os 42 restantes, como operadores. Os sistemas gerenciais de todos os gerentes-proprietários foram analisados do ponto de vista dos elementos planejamento, organização, comando e controle (POCC) de Fayol. Cada um dos dois grupos tem seu próprio sistema de atividades. Para os empreendedores, as atividades no sistema foram visão, projeto, animação, monitoração e aprendizagem; enquanto, para os operadores, as atividades foram seleção, desempenho, atribuição, alocação, monitoração e ajuste.

\section{ABSTRACT}

Based on an empirical study of the managerial systems of 116 small business owner-managers, the subjects were divided into two groups. A total of 74 were classified as entrepreneurs, and the remaining 42 as operators. The managerial systems of all the sample ownermanagers were analyzed from the point of view of Fayol's POCC elements (planning, organizing, commanding and controlling). Each of the two groups had an activity system of its own. For the entrepreneurs, the activities in the system were visioning, designing, animating, monitoring and learning, while for the operators they were selecting, performing, assigning, allocating, monitoring and adjusting.

\section{PALAVRAS-CHAVE}

Empreendedores, empreendedorismo, pequenos negócios, gerenciamento de pequenos negócios, tipologia do empreendedor.

\section{KEY WORDS}

Entrepreneurs, entrepreneurship, small business, small business management, entrepreneur typology. 


\section{INTRODUÇÃO}

A metáfora da máquina (Morgan, 1986) surgiu a partir da pesquisa de Fayol (1949) e dos trabalhos de Emerson (1912) e de Gulick e Urwick (1937). Este artigo examina os sistemas gerenciais de dois grupos de gerentes-proprietários de pequenos negócios - empreendedores e operadores - do ponto de vista das atividades gerenciais da metáfora da máquina do os modelos obtidos a partir do estudo empírico sobre o processo gerencial de gerentes-proprietários de pequenos negócios.

A pesquisa aqui descrita examina os sistemas de atividades de 116 gerentes-proprietários. Ela mostra que, ao contrário do que dizem alguns autores, os métodos gerenciais desses gerentes-proprietários não seguem a lógica formal POCC. Embora muito já se tenha dito sobre as diferenças no gerenciamento de pequenas e grandes firmas (Hartmann, 1959; Welch e White, 1981; Hoy e Carland, 1983), pouquíssimos autores (Vesper, 1994) produziram modelos gerenciais baseados em dados empíricos. A seguir, propõem-se dois modelos gerenciais medianos criados a partir dos sistemas dos dois tipos de gerentes-

(planejamento, organização, comando e controle). Em outras palavras, examina como os gerentesproprietários se comportam em relação a esses quatro elementos básicos.

\section{PROCESSO GERENCIAL}

Mintzberg (1973) descreveu a atividade do gerente como variada e fragmentada. Esses mesmos adjetivos podem ser aplicados ao trabalho dos gerentes-proprietários, que inclui diversos elementos. A questão central de nossa pesquisa é: por trás de sua quase sempre efervescente atividade, quais sistemas de pensamentos os gerentes-proprietários de pequenos negócios usam como base para suas ações?

Quando a pesquisa foi iniciada, a literatura sobre gerenciamento de pequenos negócios ${ }^{1}$ mostrava que a clássica abordagem POCC, usada genericamente para ensinar gerenciamento corporativo (Koontz e O'Donnell, 1980), era freqüentemente utilizada de forma inalterada no gerenciamento de pequenos negócios (Davis e Whybark, 1976; Scholhammer e Kuriloff, 1979; Claran, Hofer e Mahon, 1980; Hodgetts, 1982; Tate Jr. et al., 1982; Broom, Longenecker e Moore, 1983; Curtis, 1983; Fowler, 1984; Gaedek e Tootelian, 1985). Apesar de essa tendência vir se tornando menos acentuada nos últimos anos (Anderson e Dunkelberg, 1993), os elementos POCC ainda aparecem de várias formas em livros sobre gerenciamento de pequenos negócios. O mesmo parece ocorrer em cursos de gerenciamento de pequenos negócios (Vesper, 1985, 1993). Entretanto, ainda não foi desenvolvida nenhuma abordagem específica utilizan- proprietários estudados: empreendedores e operadores.

\section{METODOLOGIA E AMOSTRAGEM}

O método utilizado foi o de pesquisa aplicada, qualitativa e exploratória em sua natureza, realizada em duas partes. Na primeira fase, modelos de atividade gerencial foram identificados e classificados pela superposição dos modelos individuais de todos os agentes. Na segunda fase, os modelos desenvolvidos foram controlados e ajustados. A abordagem de sistemas sociais de Checkland (1981) foi usada para estabelecer os modelos de atividade iniciais. Ela consiste em identificar ou projetar um sistema de atividade humana baseado nas definições de raiz e estrutura conceitual utilizadas pelos agentes para desenvolver seus sistemas de atividades.

Para que pudessem ser qualificados como agentes, foi necessário que os gerentes-proprietários possuíssem mais que $50 \%$ das ações da empresa. Na realidade, somente em três casos eles não possuíam mais que $80 \%$. A Tabela 1 mostra a distribuição dos agentes por país e atividade.

O grupo usado na primeira fase compreendia 42 pequenas indústrias reconhecidas por seu sucesso. Todas ganharam pelo menos um prêmio (por exemplo, Empresa do Ano, Exportador do Ano, etc.) e foram matéria de artigos em jornais ou revistas. "Pequena indústria" foi definida como aquela que emprega até 250 pessoas.

O grupo da fase 2 incluía empresas de todos os tamanhos nos setores de manufatura, varejo e serviço. Oito grandes firmas canadenses, cada qual empregando mais de 1.000 pessoas, reconhecidas pelo 
Tabela 1 - Estudos de caso

\begin{tabular}{|l|r|c|c|}
\hline \multicolumn{1}{|c|}{ Países } & Empreendedores & Operadores & Total \\
\hline \multicolumn{3}{|c|}{} \\
\hline Finlândia & 12 & 3 & $\mathbf{1 5}$ \\
\hline Suécia & 5 & 2 & $\mathbf{7}$ \\
\hline Escócia & 10 & 1 & $\mathbf{1 1}$ \\
\hline Suíça & 1 & 8 & $\mathbf{9}$ \\
\hline Subtotal & 28 & 14 & $\mathbf{4 2}$ \\
\hline
\end{tabular}

\begin{tabular}{|l|c|c|c|}
\hline \multicolumn{3}{|c|}{ Fase 2 } & $\mathbf{7}$ \\
\hline Bangladesh & 3 & 4 & $\mathbf{4}$ \\
\hline Brasil & 2 & 2 & $\mathbf{1 9}$ \\
\hline Canadá & 6 & 13 & $\mathbf{8}$ \\
\hline $\begin{array}{l}\text { Canadá } \\
\text { (corporação) }\end{array}$ & 8 & & 3 \\
\hline Eslovênia & 3 & & $\mathbf{1}$ \\
\hline Estônia & 1 & & 2 \\
\hline EUA & 2 & 1 & $\mathbf{2}$ \\
\hline França & 1 & 4 & $\mathbf{1 2}$ \\
\hline Índia & 8 & & 4 \\
\hline Japão & 4 & & $\mathbf{2}$ \\
\hline Madagáscar & 2 & 1 & 3 \\
\hline Malásia & 2 & & $\mathbf{2}$ \\
\hline Nepal & 2 & 3 & $\mathbf{5}$ \\
\hline Tailândia & 2 & 28 & $\mathbf{7 4}$ \\
\hline Subtotal & 46 & $\mathbf{4 2}$ & $\mathbf{1 1 6}$ \\
\hline Total & $\mathbf{7 4}$ & & \\
\hline
\end{tabular}

seu sucesso e criadas por empreendedores que atualmente as administram foram estudadas com o objetivo de confirmar a validade do modelo de empreendedor visionário identificado. Em Bangladesh, na Estônia, na Eslovênia e na Tailândia, os negócios estudados apresentavam entre 5 e 20 empregados cada. Em todos os outros casos, eles eram de porte médio.

Entrevistas semi-estruturadas com duração de três a cinco horas foram realizadas com cada gerenteproprietário. Na Escócia, entrevistas semi-estruturadas com duração de uma a duas horas também foram feitas com todas as pessoas em contato direto com os gerentesproprietários (empregados, executivos, membros de diretoria e gerentes bancários). Todas as entrevistas, com exceção daquelas feitas na Escandinávia, foram gravadas.

A pesquisa cobriu o período entre 1985 e 1993. Na Tabela 1, as empresas da fase 1 (1985-1986) são mostradas por país em ordem cronológica, e as empresas da fase 2 (1986-1993), por país em ordem alfabética, uma vez que, neste último caso, alguns países foram visitados mais de uma vez no período em questão.

Após as entrevistas, os gerentes-proprietários foram classificados como empreendedores ou operadores com base na inovação. Em outras palavras, se eles introduziram alguma inovação mais significativa como, por exemplo, um novo produto ou um novo mercado, eles foram classificados como empreendedores. Em quase todos os casos, os empreendedores lideravam empresas em crescimento. Esse grupo corresponde à categoria crescimento, autonomia e perenidade (CAP) de Julien e Marchesnay (1987), e o grupo de operadores pertence à categoria perenidade, independência e crescimento (PIC). Apenas quatro dos empreendedores eram mulheres.

O autor já publicou alguns textos e livros tratando de sistemas de empreendedorismo de empreendedores bem-sucedidos (Filion, 1991c, 1994a), da metodologia usada (Filion, 1991c, 1993a), dos impactos dos modelos empreendedores sobre o gerenciamento estratégico (Filion, 1989b, 1993b, 1994a) e das conseqüências dos modelos para o processo gerencial de pequenos negócios (Filion, 1994b, 1994c, 1995). Este texto examina o último aspecto em maiores detalhes, embora a discussão esteja restrita aos elementos-chave da metáfora da máquina: planejamento, organização, comando e controle.

\section{O PROCESSO DE GERENCIAMENTO EMPREENDEDOR}

Os sistemas de atividades humanas podem ser mapeados ou representados de formas diferentes, mesmo quando, como é o caso aqui, os limites do sistema são fixados em torno dos elementos POCC. As opções dos pesquisadores tornam-se mais claras à medida que mais dados são coletados. Após cinco ou dez casos, as tendências se delineiam. Os casos subseqüentes servem para esclarecer, refinar, ajustar e controlar o modelo produzido, nesse ponto utilizando-se a estrutura de Checkland para sobrepor os modelos obtidos a partir de casos e análises anteriores. A Figura 1 ilustra os cincos elementos principais no processo gerencial dos empreendedores, e o Quadro 1 lista vários fatores compostos por cada elemento. As atividades gerenciais baseiam-se nesses elementos. Em outras palavras, eles fornecem a estrutura na qual os empreendedores desempenham suas atividades gerenciais. As seções seguintes descrevem e explicam os cinco elementos e comentam como o processo funciona. 
Figura 1 - 0 processo gerencial dos empreendedores

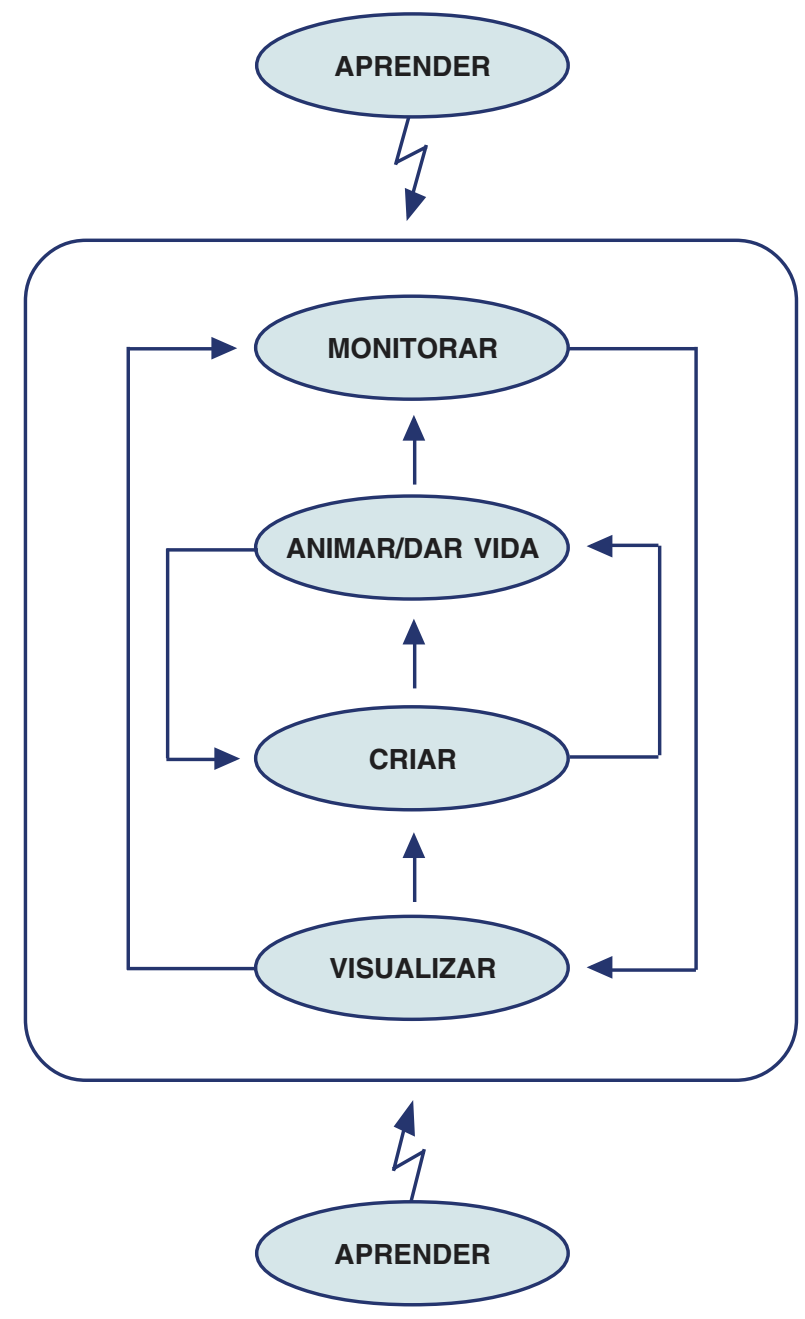

\section{O processo da construção da visão ${ }^{2}$}

Visão é aqui definida como: "a imagem projetada no futuro do espaço de mercado futuro a ser ocupado pelos produtos e o tipo de organização necessária para se alcançar isso" (Filion, 1991b, p.109-10). Foram identificadas três categorias de visão: a visão emergente (idéias para futuros produtos e serviços); a visão central (o resultado de uma ou mais visões emergentes) em duas partes: a parte externa, ou seja, a faixa de mercado a ser ocupada por um produto ou serviço, e a parte interna, ou seja, o tipo de organização necessária para tornar isso realidade, e, por fim, a visão complementar ou as atividades gerenciais necessárias para dar suporte à concretização da visão central (Filion, 1991b). O processo visionário compreende seis elementos compostos, desenvolvidos de forma consecutiva. Esses elementos estão demonstrados em forma de diagrama na Figura 2.
O interesse do empreendedor em um setor de negócios específico pode ter origem em fontes diversas. Ele é provocado por um dos três níveis de relações (primárias, secundárias e terciárias) (Filion, 1989a, 1989b, 1990a, 1991b). Quanto mais novo for o empreendedor no início do processo, maior será a influência do ambiente familiar (relações primárias). Quanto mais velho for o empreendedor, maior será a influência dos contatos com o meio de negócios (relações secundárias) ou da experiência prévia e das atividades de aprendizagem, freqüentemente ligadas ao trabalho (relações terciárias).

Inicialmente, o interesse em uma área particular é um tanto vago, mas tende a tornar-se mais claro com o passar do tempo, embora nenhum dos gerentes-proprietários entrevistados para esta pesquisa tivesse uma idéia clara de onde eles estariam num prazo de dez anos. Tal interesse constitui a base do que virá a ser a definição fundamental, ou pivô, do sistema. O progresso depende da habilidade de instituir métodos de trabalho e de se concentrar em uma ou algumas visões emergentes. O interesse inicial conduz o empreendedor a focalizar, examinar, analisar e tentar entender o setor escolhido.

Figura 2 - 0 processo visionário

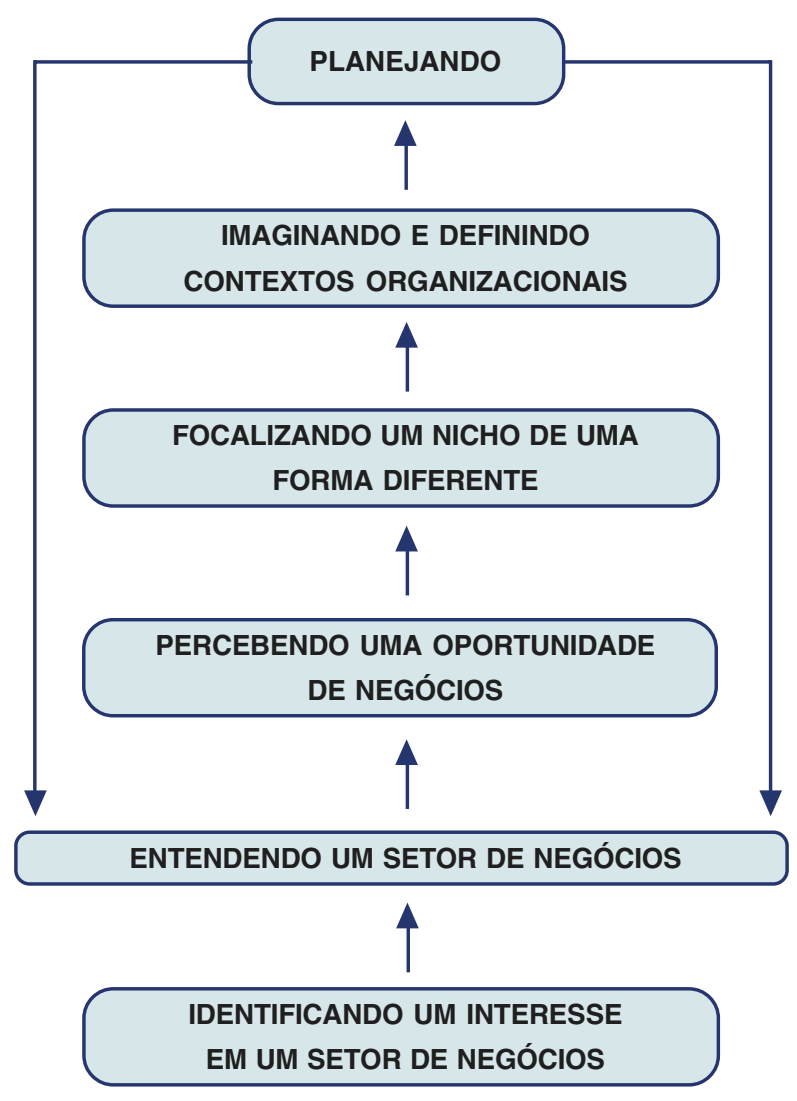


Entender demanda um nível mínimo de conhecimento. A visão é uma imagem projetada de uma situação de futuro desejada - um sonho realista e alcançável. Quanto mais completo for o conhecimento do empreendedor e, ainda, sua imagem e entendimento de um setor de negócios, tanto mais realista será sua visão. É difícil visualizar um nicho do mercado a ser ocupado no futuro sem um claro entendimento dos espaços já ocupados por outros no setor. Pelo menos seis elementos estão envolvidos nesse processo: a capacidade intelectual e o nível de instrução do empreendedor, a posição ocupada quando a informação foi adquirida e a razão dessa aquisição, o quanto o empreendedor conhece o setor e, finalmente, o tempo gasto para se inteirar sobre o setor. Esse último elemento poderá variar bastante dependendo da complexidade relativa do setor em questão. Em nossa amostragem, não observamos nenhuma correlação entre nível de instrução, sucesso na educação, disciplina estudada e sucesso nos negócios. Por outro lado, os empreendedores mais novos e menos experientes certamente necessitavam de mais tempo para entender como o setor funcionava. Gerentes-proprietários com um passado de família empreendedora têm clara vantagem aqui, uma vez que a aprendizagem informal parece ser mais importante que o ensino formal. A posição ocupada no momento da aquisição do conhecimento de mercado e a razão dessa aquisição determinam o ângulo e o ponto de vista, bem como até aonde se tem que ir no processo de aquisição de conhecimento. Pessoas com experiência em vendas e marketing levam vantagem inicial. Se eles começarem seu próprio negócio, adquirirem ou desempenharem algum papel na gerência geral, vendas ou marketing em alguma empresa existente, as suas chances de criar uma visão de forma precisa crescerão no mesmo ritmo do seu entendimento do mercado, que, por outro lado, parece mais completo, por eles terem tido contato mais prolongado com mais atores do se-

Quadro 1 - Atividades do processo gerencial dos empreendedores

\begin{tabular}{|c|c|}
\hline Principais elementos & Elementos componentes \\
\hline $\begin{array}{l}\text { Visualizar } \\
\text { (ver Figura 2) }\end{array}$ & $\begin{array}{l}\text { - Identificar um interesse num setor de negócios. } \\
\text { - Entender um setor de negócios. } \\
\text { - Detectar uma oportunidade de negócios. } \\
\text { - Imaginar e definir um contexto organizacional. } \\
\text { - Planejar. }\end{array}$ \\
\hline $\begin{array}{l}\text { Criar uma arquitetura } \\
\text { de negócios }\end{array}$ & $\begin{array}{l}\text { - Formular visões complementares, atividades e tarefas gerenciais a serem desempenhadas. } \\
\text { - Estruturar o sistema de atividades. } \\
\text { - Organizar. }\end{array}$ \\
\hline
\end{tabular}

Animar/dar vida
- Ligar as tarefas aos recursos humanos.

- Recrutar, selecionar e contratar recursos humanos.

- Dirigir os recursos humanos para a realização das visões complementares.

- Comunicar, motivar.

- Liderar.
Monitorar

Aprender
- Monitorar as realizações e os recursos usados, incluindo o tempo.

- Comparar com as previsões e analisar diferenças.

- Corrigir, ajustar, melhorar.

- Em qualquer nível, questionar o que foi feito e como foi feito.

- Considerar as alternativas.

- Buscar elementos de consistência.

- Raciocinar.

- Imaginar.

- Definir e redefinir a visão central e as visões complementares. 
tor-alvo. O tempo necessário para entender um setor e começar a desenvolver visões nele depende de todos esses elementos e também, mais particularmente, da competência do empreendedor em negócios e da complexidade do setor. Nossas entrevistas com empreendedores que começaram seus negócios ainda bem jovens mostraram que, em todos os casos, foram necessários entre cinco e dez anos para compreender suficientemente o setor. David Murray, Empresário do Ano de 1994 na Escócia (Filion, 1988, 1990b), tinha apenas 16 anos quando começou a vender sucata, 24 quando comprou uma empresa do setor e 28 quando começou a desenvolver trabalhos diferenciados. Gio Benedetti (Filion, 1988, 1990b) tinha 11 anos quando começou a trabalhar em regime de meio expediente no negócio da família, 19 quando comprou uma empresa de lavagem a seco e quase 30 quando finalmente começou a reciclar luvas industriais, atividade na qual fez sua fortuna. É difícil medir a compreensão que um empreendedor tem sobre um setor de negócios. Alguns levaram 10 anos, outros, 20 anos, e um determinado número de empreendedores jamais irá atingir um bom nível de entendimento. Os empreendedores de nossa amostragem que tinham grande experiência num setor e que, em seguida, começaram um negócio bemsucedido em outro trabalharam bastante por um ou dois anos antes de terem adquirido conhecimento suficiente do novo setor para levar adiante seus planos ou, em outras palavras, para conceber um nicho ou espaço a ser ocupado de uma nova maneira.

Para detectar oportunidades de negócios, é preciso ter intuição, intuição requer entendimento, e entendimento requer um nível mínimo de conhecimento. Nenhum dos empreendedores entrevistados para a pesquisa havia detectado alguma oportunidade, começado um negócio e obtido sucesso sem um profundo conhecimento prévio e uma compreensão do setor. Como mostram os exemplos anteriores de Murray e Benedetti, entretanto, acontece freqüentemente (em quase $50 \%$ dos casos) de o empreendedor perceber intuitivamente que um setor em particular oferece oportunidades interessantes. Eles seguem em frente explorando e trabalhando nesse setor, mas poderão levar alguns anos para identificar o nicho que irão finalmente ocupar. Aqui, a ação de "detectar" tem mais em comum com consciência, sugestão ou intuição. Durante a discussão sobre intuição em um seminário, uma das participantes, uma mãe, lembrou que a "intuição feminina" vem principalmente do seu papel como mãe. Ela conhece seus filhos tão bem que, se eles se comportam de forma diferente, ela imediatamente tem a intuição de que algo de "anormal" está acontecendo. Por quê? Porque o comportamento deles naquele dia não é o usual. Embora o seu valor seja questionável como exemplo, a analogia com o empreendedor é, no entanto, interessante. Um empreendedor terá a intuição de que algo é possível em um mercado em particular porque ele conhece o mercado o suficiente para entender seu funcionamento e ser capaz de detectar oportunidades. O processo caminha do geral para o específico. A oportunidade quase sempre consiste em ocupar um segmento que ninguém tenha pensado em ocupar dessa maneira antes.

Alguns dos empreendedores entrevistados não introduziram nenhum produto ou inovação de mercado relevante, mas inovaram ao reduzir custos, melhorar a qualidade ou oferecer serviços mais rápidos. Essa foi a oportunidade por eles identificada e foi isso que lhes deu a sua margem competitiva. Um número crescente de oportunidades parece advir do fator "tempo", não apenas na escolha do momento certo, mas no oferecimento de um produto ou serviço num espaço de tempo mais curto. Nossa pesquisa sugere que os empreendedores que obtiveram sucesso são aqueles que caminharam passo a passo, gradualmente. Eles aprenderam a concentrar, a estabelecer limites para sua atividade, a definir essa atividade e a escolher um alvo a ser atingido. A escolha do alvo inicial e os seus ajustes graduais e subseqüentes fazem toda a diferença. Nesse aspecto, os empreendedores são um tanto quanto estrategistas. Será difícil, se não impossível, para os empreendedores concretizar suas visões se não aprenderem a focalizar um alvo. Alguns dos empreendedores tiveram um número enorme de idéias brilhantes, mas jamais aprenderam a focalizar, a concentrar, e por isso seus negócios não prosperaram. Os elementos básicos do processo visionário parecem ser o entendimento do setor, a habilidade de identificar uma necessidade não satisfeita - e, portanto, uma oportunidade de negócio - e a imaginação para refletir e selecionar um nicho a ser ocupado de forma diferente.

O espaço ou nicho de mercado a ser ocupado, uma vez identificado, forma o elemento central em torno do qual o empreendedor imagina e define o contexto organizacional necessário para se alcançar o fim desejado. Criar uma visão significa, essencialmente, identificar e dar sentido ou direção às atividades subsequientes. Os empreendedores aprendem a conhecer e entender seus setores. Eles detectam possibilidades de negócios, imaginam, definem e selecionam um espaço de 
mercado que pretendem ocupar e, então, concebem o tipo de organização necessário para fazê-lo. Uma vez que a visão foi imaginada, ela é desenvolvida, corrigida e ajustada, não em termos de seu conteúdo básico, mas em termos das muitas atividades diferentes necessárias para que se prossiga na direção da concretização da

\section{Quanto mais velho for o empreendedor,} maior será a influência dos contatos com o meio de negócios ou da experiência prévia e das atividades de aprendizagem.

mais existiam antes de empregados de nível executivo passarem a integrar a empresa. Os empreendedores pareciam desenvolver planos informais, freqüentemente sem material escrito, em suas cabeças, baseados ou guiados pela visão. Em todos os casos, eles tinham um alvo ou objetivo e haviam estabelecido alguns pontos de referência, mas fizeram ajustes ao longo do caminho.

$\mathrm{O}$ processo visionário fornece os elementos de consistência que distinguem os empreendedores: conhecimento e entendimento do mercado e a combinação dos níveis de sistemas de relações internas e externas com o nível da visão. Esses dois aspectos são de fato determinantes do suces-

visão. A visão não é estática, ela é um processo em constante evolução. A maneira como ela evolui depende do sistema de relações do empreendedor. Serão as pessoas ao redor do empreendedor que possibilitarão que a visão seja realizada e desenvolvida. A visão em si mesma e as atividades necessárias para concretizá-la tornam-se critérios implícitos na seleção dos colaboradores. Isso tem um papel fundamental na explicação do sucesso futuro.

O coração do processo de empreendedorismo - e o aspecto que melhor distingue o empreendedor do gerente e do pequeno empresário - parece recair no desenvolvimento e na implementação do processo visionário. Gerentes e pequenos empresários buscam atingir metas e objetivos a partir dos recursos disponíveis, dentro de uma estrutura predefinida ou copiada. Os empreendedores, por outro lado, gastam boa parte de seu tempo imaginando aonde querem chegar e como farão para chegar lá. De alguma forma, os empreendedores são detectores de espaços de mercado e criadores de contextos. Uma vez detectada a oportunidade, a visão fornece diretrizes para a implementação do plano mestre.

É aqui que o planejamento em suas várias formas pode desempenhar o seu papel. Poucas das firmas da amostragem, bem-sucedidas ou não, possuíam algum tipo de planejamento formal detalhado. O planejamento parece depender da demanda financeira e do tamanho da empresa. Somente quando uma organização financeira solicitou planos ou a empresa cresceu substancialmente foi que os empreendedores estudados apresentaram ferramentas de planejamento detalhadas, tais como orçamentos ou planos estratégicos. Em todos os casos estudados, pouquíssimos planos for- so empresarial e da real possibilidade de concretização da visão.

\section{Projetar uma arquitetura de negócios}

Projetar uma arquitetura de negócios significa criar uma estrutura organizacional ou estrutura funcional na metáfora da máquina descrita por Fayol (1949). Posteriormente (Koontz e O’Donnell, 1980), esse conceito foi ampliado para incluir elementos como: produto, região, processo de manufatura, cliente e outros, criando-se um formato de estrutura matricial (Nadler, Gerstein e Shaw, 1992).

Para os empreendedores, o processo de criar e definir uma arquitetura de negócios baseia-se no espaço de mercado que desejam ocupar. Eles identificam um nicho e imaginam o tipo de estrutura necessária para ocupá-lo, em outras palavras, a visão central interna. Eles definem tarefas a serem desempenhadas (as visões complementares) e, então, identificam os recursos humanos necessários. Aqui, as visões complementar e central interna - as atividades gerenciais a serem desenvolvidas e o tipo de organização necessário para desempenhá-las - estão intimamente ligadas. As visões complementares emergem inicialmente da visão interna central a qual elas subseqüentemente ajudam a fruir gradualmente. Muitos dos empreendedores entrevistados chamaram a nossa atenção para a dificuldade em se definir tarefas a serem desempenhadas e o problema de combinar essas tarefas com os recursos humanos necessários. Na fase inicial, alguns dos trabalhos poderão ser feitos à noite ou em regime de meio expediente por algum conhecido do empreendedor. Há uma clara tendência para a subcontratação ou terceirização. Esse fenômeno, que se tornou uma constante nos seto- 
res público e privado, afeta os pequenos negócios de várias maneiras. Muitas firmas de crescimento rápido já vêm terceirizando há alguns anos, e a terceirização também proporciona muitas oportunidades para pequenos negócios. Cerca de $60 \%$ dos empresários asiáticos entrevistados nesta pesquisa existem como tal em função de trabalho subcontratado de um ou dois clientes nos EUA ou na Europa. Mais recentemente, o mundo diz: "a responsabilidade primordial desta pessoa é o serviço ao cliente". Em outras palavras, o serviço ao cliente é a razão de viver de cada um dos empregados da organização, e espera-se que eles adotem uma postura de marketing voltada para o cliente em tudo o que fazem (Filion, 1990b).

Outras firmas da amostragem, mesmo aquelas empregando mais de cem pessoas, possuíam pouquíssimos níveis hierárquicos. Algumas estabeleceram um sistema no qual cada empregado possui um alto nível de responsabilidade, fazendo com que a organização funcione como um relógio automático, com pouca ou nenhuma necessidade de intervenção externa. O papel dos empregados era desenvolver um pro-

ocidental tem caminhado na direção de um modelo de empresa em que uma pequena unidade, composta de alguns poucos vice-presidentes altamente eficientes, irá gerenciar praticamente tudo por meio da terceirização. Um pequeno grupo de pesquisa e desenvolvimento, sob a direção de um vice-presidente (VP), irá criar produtos com base em pesquisas de mercado subcontratadas pelo VP de Marketing. O VP Financeiro irá negociar financiamento, o VP de Operações irá terceirizar a produção no chamado Cinturão Amarelo (entre Japão e Cingapura), o VP de Vendas irá distribuir, e o VP de Marketing irá terceirizar a publicidade para uma agência. É mais ou menos assim que Paul Fireman descreve a empresa Reebok, que expandiu suas vendas de US\$ 30 mil em 1979 para US\$ 2 bilhões em 1989 ao terceirizar praticamente tudo, exceto a distribuição. Os métodos e as atividades gerenciais que possibilitam a terceirização requerem uma arquitetura organizacional imaginativa. A ênfase recai não sobre a produção, mas sobre a criação do produto e sobre o marketing.

A estrutura de arquitetura imaginada por quase todos os empreendedores bem-sucedidos entrevistados era a de uma forma de empresa original que não obedecia às regras de estrutura organizacional ou hierarquia, mas que eram ideais para se alcançar suas próprias visões centrais externas. Por exemplo, a Jean Coutu Drugstores, uma rede de drogarias altamente bem-sucedida em Quebec, Canadá, não possui departamento de marketing e, no entanto, é conhecida pelas suas agressivas estratégias de marketing. Cada nome no organograma do grupo está marcado com um asterisco, que conduz o leitor a uma nota de rodapé que duto ou mercado, estruturar seu desenvolvimento sob a autoridade de outra pessoa e prosseguir desenvolvendo outras coisas.

A literatura sobre gerenciamento mais recente tem muito a dizer sobre conceitos como reengenharia, downsizing e rightsizing (Davenport, 1993; Hammer e Chamky, 1993). Os dados coletados nesta pesquisa mostram que os empreendedores agem de acordo com esses conceitos e geralmente concebem suas organizações de modo a usar os recursos parcimoniosamente. Eles aprenderam a manter organizações enxutas com ênfase nas funções e responsabilidades. A função de aconselhamento é praticamente ausente. A ênfase está na visão, na missão e nas operações. Os empregados trabalham duro e são comprometidos com o que fazem.

A experiência do empreendedor no setor é extremamente valiosa, especialmente na empreitada de criação inicial, tão crucial para o sucesso. É aqui que os empreendedores podem organizar seus negócios para operar com poucos recursos terceirizando e investindo menos em infra-estrutura de produção. Isso lhes dará tempo para assuntos mais essenciais, tais como estratégia e gerenciamento.

\section{Animação}

A visão funciona como estrutura diretriz e fornece ao empreendedor indicadores para organizar e desempenhar atividades. Isso também serve como critério para a seleção de novos recursos, especialmente recursos humanos. Da mesma forma que para a criação, a animação inclui elementos internos e externos, tais como terceirização. O papel gerencial de gerentes-proprietários empreendedores parece ser mais afinado com o 
animar ou dar vida do que com o gerenciar. Empreendedores de sucesso investem mais tempo, energia e recursos que os demais em recrutamento, seleção e treinamento de recursos humanos competentes e adequados. Eles também expendem mais tempo comunicando aquilo que desejam alcançar, a sua visão, o que esperam e as suas visões complementares. O seu exemplo de liderança e energia age como força motriz ou catalisador, e as pessoas ao seu redor têm que realizar muito, freqüentemente com poucos recursos e em espaços de tempo bem curtos. A atenção concentra-se na

anos, e, em alguns casos, enquanto permanecerem no negócio. Por exemplo, um dos filhos de Jean Coutu é agora o diretor-geral ${ }^{3}$ da firma, que tem milhares de empregados, mas Coutu permanece como diretor e ainda mantém o controle sobre a publicidade (a chave do sucesso da firma) a despeito dos seus 65 anos (Filion, 1990b).

\section{Monitoração}

O termo "controle" significa inspecionar ou examinar algo de perto, em detalhes ou sistematicamente. Isso freqüentemente implica autoridade ou alguma forma de dominação. "Monitoração", por outro lado, quer dizer supervisionar ou observar desenvolvimentos. Isso envolve acompanhamento para assegurar coerência interna. O foco do interesse está no resultado geral. O objetivo não é controlar cada parte do sistema, mas monitorar o

atividade. $\mathrm{O}$ empreendedor inicia uma dinâmica que demanda uma interação contínua entre os operadores e o processo criativo. Inicialmente, a presença do empreendedor tem uma forte influência na relação entre criação e dinâmica. Posteriormente, com as pessoas treinadas e podendo desenvolver o trabalho adequadamente, o empreendedor desloca-se para novas atividades. Empreendedores em empresas de crescimento rápido tendem a delegar tudo o que podem e trabalhar apenas no desenvolvimento.

Quando analisamos as partes das entrevistas que se referiam a gerenciamento ou animação de empresas, sempre anotamos observações sobre a imaginação e o julgamento apresentados. O que se vê nessas empresas não é gerenciamento no sentido clássico, mas um tipo de imaginação que é mais invasiva, mais completa e também mais motivante. A visão tem um papel-chave num processo em que todos trabalham com convicção rumo a um objetivo.

Empreendedores delegam mais facilmente que operadores porque parecem mais capazes de desenvolver uma visão geral de toda a tarefa e o papel dela na organização. Eles parecem ter percebido que a sua ação terá maior impacto se eles delegarem mais trabalho trivial e se concentrarem no desenvolvimento e na criação de novos elementos. Entretanto, muitos deles não delegam tarefas em suas áreas originais de especialidade. Empreendedores cujo primeiro interesse é pesquisa e desenvolvimento, produção ou vendas continuarão a gerenciar esses setores, freqüentemente por muitos desenvolvimento geral de olho no resultado final. Isso não quer dizer que o empreendedor não vá intervir de forma alguma. Significará, de fato, entretanto, que o controle tenderá a não ser restritivo, mas que será exercido com a visão de aprender para corrigir, ajustar e fazer melhorias.

Aqui deve ser feita uma distinção entre monitoração no sentido gerencial e monitoração no sentido contábil. De todos os empreendedores da amostragem, apenas um mantinha controle total das despesas e assinava todos os cheques. Em empresas de crescimento rápido com mais de 250 empregados, isso demanda muito tempo. Durante a entrevista com aquele empreendedor em particular, na Escócia, um empregado interrompia a cada 10 ou 15 minutos para obter autorização de alguma despesa (algumas vezes de apenas algumas libras) ou para ter um cheque assinado. Um parente próximo era responsável por destrancar e trancar as portas pela manhã e pela noite. Outros parentes trabalhavam em diferentes departamentos da empresa e asseguravam que os empregados fizessem seu trabalho sem usar recursos em demasia. Em todos os outros casos, os empreendedores simplesmente monitoravam a contabilidade em caráter periódico, algumas vezes semanalmente, mas, na maioria das vezes, mensalmente.

Monitoração no sentido gerencial parece ser uma preocupação mais constante entre empreendedores do que entre operadores. Os empreendedores criam tarefas e então acompanham desenvolvimentos, fazendo ajustes periódicos até que atinjam uma forma de ope- 
ração apropriada, efetiva e eficiente. Em seguida, eles monitoram a situação esporádica e seletivamente. Se surge algum problema, eles intervêm, dessa vez com medidas corretivas de maior vulto. Eles analisarão as razões por detrás do problema. Quase sempre, eles irão reestruturar todas as atividades relacionadas. Tudo depende das circunstâncias. Entretanto, os empreendedores parecem propensos a usar todo o poder proveniente da sua condição de proprietário para estruturar e reestruturar elementos que não funcionam até atingirem o resultado desejado. Essa é uma de suas forças e uma evidente vantagem competitiva.

Entretanto, descobriu-se que a monitoração era o "tendão de Aquiles" da maioria dos empreendedores da amostragem. Nos primeiros dias do início da empresa, pouquíssimo planejamento é feito e, portanto, existem raras diretrizes específicas para avaliar os resultados em termos de tempo gasto, artigos produzidos e recursos usados. É importante lembrar que essas pessoas freqüentemente trabalham com elementos novos ou diferentes, o que significa que elas têm muito poucos pontos de referência. Em geral, observamos muito poucos controles detalhados, como os que se encontram em grandes firmas. Ao contrário disso, os empreendedores faziam uma monitoração seletiva em caráter esporádico. A monitoração não era um elemento maior nas atividades gerenciais de nossos empreendedores. Eles não a julgavam importante e, assim, isso só foi feito adequadamente quando eles encontraram alguém a quem pudessem delegar essa tarefa. Com o crescimento da empresa, o processo de monitoração tendeu a se tornar mais formalizado, até tornar-se bem parecido com o controle de tipo contábil largamente praticado em grandes firmas.

\section{Aprendizagem}

Empreendedores de sucesso nunca param de aprender. Collins e Moore (1970) foram uns dos primeiros que identificaram isso como uma das características mais marcantes dos empreendedores bem-sucedidos. A aprendizagem, a aquisição e a expressão de knowhow gerencial e técnico tornam-se o modo de vida dos empreendedores de sucesso. Trata-se de uma forma contínua e freqüentemente bem detalhada de monitoração-reflexão-digestão do que está acontecendo. Isso conduz à correção, ao ajuste e à melhora do que é feito e de como é feito. Os empreendedores são incentivados a aprender pela sua visão, o que também lhes ajuda a estabelecer diretrizes para aquilo que precisam aprender. Cerca de 10\% dos empreendedores da amostra haviam sido diletantes, "curiosos" ou aventureiros sem qualquer interesse em aprender antes de identificarem sua visão. A visão parece ter criado um centro de interesse que os motivou a fazer mudanças em suas vidas.

Ao percorrerem o processo visionário, empreendedores tornam-se mais motivados a aprender. Em geral, eles gostam de aprender em contato direto e trabalhando com uma matéria concreta, e quase todos têm dificuldade de lidar com abstrações, como, por exemplo, noções de estratégia. Isso se aplica, sobretudo, a empreendedores sem formação universitária. Essa cultura e estilo de vida de aprendizagem não são sempre compartilhados com os que o cercam, a não ser quando as coisas não funcionam. Em tais casos, serão feitas reuniões de grupo e "post-mortems" para tentar estabelecer exatamente o que deu errado. Enquanto continuam a aprender, os empreendedores continuam a ter sucesso.

As seções seguintes abordarão as atividades do processo gerencial dos operadores e irão compará-las às atividades dos empreendedores.

\section{PROCESSO GERENCIAL DOS OPERADORES}

As atividades do processo gerencial de operadores de pequenos negócios - aqueles que não introduziram nenhum produto ou inovação de mercado mais relevante e cujos negócios não cresceram rápido - parecem ser muito mais limitadas que as atividades dos empreendedores. Cerca de $80 \%$ dos operadores adquiriram seu negócio ou assumiram a parte de um sócio e não desempenharam nenhum papel-chave na criação do empreendimento. Em $90 \%$ dos casos, a empresa permaneceu pequena (menos de 20 empregados no setor manufatureiro), e os operadores podem ser chamados, sem dúvida, de "banda de um músico só". Na maioria dos casos, a empresa não poderia sobreviver à ausência do seu líder por mais de alguns dias ou, no máximo, algumas semanas. A Figura 3 mostra as atividades do operador em forma de diagrama e o Quadro 2 fornece uma descrição sumária delas.

\section{Seleção}

Operadores de pequenos negócios identificam e selecionam um setor de negócios. Seus critérios de seleção parecem basear-se em suas próprias habilidades. Em outras palavras, eles irão escolher um setor que corresponda ao treinamento de suas habilidades ou vocação, freqüentemente adquirido em contato direto 
Figura 3 - O processo gerencial dos operadores

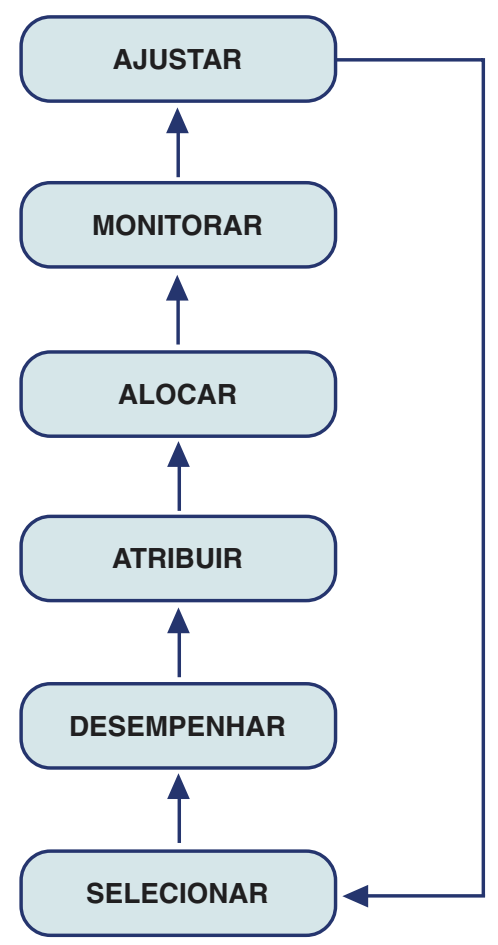

com a experiência. Eles selecionam um setor potencial porque sabem que poderão usar suas habilidades já adquiridas ou desenvolver novas habilidades que lhes permitirão operar dentro dele. Considerações sobre o mercado estão presentes, mas não parecem ser tão importante quanto a competência ou perícia no campo escolhido. Alguns operadores buscam uma empresa em um campo em particular porque se sentem confiantes no sucesso, devido à sua experiência ou perícia. Outros assumirão um negócio de família e continuarão por opção a gerenciá-lo nos mesmos termos de antes, exceto por alguns pequenos ajustes. Em alguns casos, os operadores da amostragem haviam realmente iniciado um negócio, mas somente porque as circunstânci- as os forçaram a fazê-lo. Por exemplo, um parente ou conhecido lhes ofereceu uma chance de terceirização.

\section{Desempenho}

$\mathrm{Na}$ maioria dos casos, os operadores de pequenos negócios desempenham sozinhos a maior parte das tarefas técnicas, gerenciais e de negócios. Isso é particularmente verdade em pequenos negócios, sobretudo na Ásia, onde os operadores gastam muito tempo trabalhando em produção ou vendas, operando equipamento ou substituindo empregados ausentes. Mesmo em negócios de porte médio com empregados qualificados, os operadores acompanham a operação bem de perto e parecem deixar menos espaço de manobra para seus empregados do que os empreendedores deixariam. Eles gastam mais tempo que os empreendedores em atividades do dia-a-dia, como, por exemplo, o acompanhamento de pedidos. No sistema do operador, os fluxos organizacionais são menos caóticos e mais regulares que em muitos dos negócios liderados por empreendedores. Por exemplo, o trabalho tende a concentrar-se em torno da área de especialidade do operador. Em negócios operados por empreendedores, horas extras são comuns, bem como são desenvolvidos novos métodos, novos produtos e novos usos para os produtos existentes.

Operadores de pequenos negócios têm princípios que os guiam, mas estes estão longe de ser as bem articuladas visões dos empreendedores, embora raramente os empreendedores tenham visões absolutamente claras. Até certo ponto, todo mundo tem uma visão de algum tipo, ou já pensou, ainda que rapidamente, sobre seu projeto de vida. Mas, para o operador, isso não é um projeto visionário estruturado como descrito anteriormente.

Os sistemas operacionais de operadores de pequenos negócios parecem estar muito próximos daquilo

Quadro 2 - Atividades do processo gerencial dos operadores

\begin{tabular}{|c|c|}
\hline Selecionar & - Identificar e selecionar um setor de negócios. \\
\hline Desempenhar & - Desempenhar atividades técnicas, gerenciais e de negócios. \\
\hline Atribuir & - Usar recursos humanos e atribuir tarefas. \\
\hline Alocar & - Viabilizar os recursos materiais necessários para se desempenharem as tarefas. \\
\hline Monitorar & - Monitorar um pouco do que é feito. \\
\hline Ajustar & - Corrigir os métodos. \\
\hline
\end{tabular}


que precisa ser feito. Os operadores realizam muito, mas parecem gastar menos tempo comunicando o que eles querem fazer - uma visão - e menos tempo discutindo o "como". Em muitas dessas empresas, o tempo de comunicação é limitado. A maior parte do esforço vai para o desempenho de tarefas concretas. Discussões sobre desenvolvimento de mercado e visões foram consideradas perda de tempo pela maioria dos operadores da amostragem. Eles achavam que deveriam apressar as coisas. Mais importante ainda, se eles não fizessem isso, correriam o risco de não ter dinheiro em mãos para pagar o salário da semana ou do mês seguinte.

\section{Para detectar oportunidades de negócios, é preciso ter intuição, intuição requer entendimento, e entendimento requer um nível mínimo de conhecimento.}

\section{Atribuição}

Não apenas os operadores preferem os aspectos concretos dos negócios às noções abstratas, mas suas relações e sua comunicação com as pessoas ao seu redor parecem ser bastante voltadas para a tarefa. Eles valorizam as pessoas que fazem aquilo que têm que fazer de forma rápida e bem feita. Embora sejam atribuídas tarefas regulares aos empregados, pede-se que eles sejam flexíveis de forma a responder ao inesperado, especialmente no setor de serviços. Entretanto, mais uma vez, operadores de negócios de médio porte e, sobretudo, operadores de pequenos negócios tendem a ficar de olho nas operações. Cada empregado tem uma tarefa principal a cumprir, mas são freqüentemente chamados a cumprir outras tarefas da mesma forma. Esse fenômeno também foi observado em negócios liderados por empreendedores. Por definição, um negócio de pequeno ou médio porte carece de recursos e necessita de arquiteturas organizacionais de tipo orgânico, em que ajustes são feitos diariamente em resposta a eventos e circunstâncias, tais como ausências, pedidos inesperados, problemas com os caminhões de entrega e assim por diante. A diferença entre as companhias lideradas por operadores e aquelas lideradas por empreendedores é que nas primeiras os próprios operadores estão no centro da ação, orquestrando ajustes a cada dia para que o negócio continue a funcionar. Empreendedores, por outro lado, treinam seus empregados para lidar com o inesperado. Em outras palavras, para os operadores, o processo de visualizar, criar e animar permanece em estágio embrionário. Eles estão mais preocupados em atribuir tarefas para obter resultados concretos e imediatos.

\section{Alocação}

Os operadores usam os recursos parcimoniosamente. Seus recursos humanos têm que trabalhar muito e usar o mínimo de recursos materiais. Os operadores monitoram o uso de recursos bem de perto e, como estão sempre com capital curto, irão esperar até repor equipamento, comprar novo maquinário ou introduzir novos processos fabris.

De fato, o triângulo no qual a maioria das atividades do processo gerencial dos operadores parece ocorrer é definido por três elementos: desempenhar tarefas baseadas num planejamento altamente informal, atribuir tarefas a serem desempenhadas e alocar recursos. Decisões importantes para a empresa - decisões que levam tempo - parecem depender em muito deste último elemento. Por exemplo, um operador algumas vezes irá agonizar durante anos ante a decisão de comprar um novo equipamento antes de finalmente tomar uma atitude.

\section{Monitoração e ajuste}

Para operadores, mais que para empreendedores, a monitoração é uma atividade sumária, altamente seletiva e quase inexistente, geralmente associada às informações contábeis. Praticamente todos os proprietários de pequenos negócios estudados nesta pesquisa não tinham idéia do seu preço de custo. Os gastos eram acompanhados de perto para saber se estavam obtendo lucro, e os custos operacionais eram mantidos no nível mais baixo possível. Entretanto, a monitoração do que estava sendo feito dentro da empresa e de como isso estava sendo feito, tendo em vista o aprendizado e a melhoria, pareceu ser bem menos sistemática em empresas comandadas por operadores do que em empresas comandadas por empreendedores. Os operadores monitoram elementos específicos visando a fazer pequenos ajustes, algumas vezes métodos, mas bem mais freqüentemente recursos, especialmente matéria-prima. Operadores levam adiante monitorações técnicas e al- 
gum controle contábil, mas pouquíssima monitoração gerencial. Para eles, o que interessa é chegar a uma operação que produza resultados satisfatórios tendo em vista o dinheiro e o tempo investidos. agora abordou essa questão a partir da perspectiva das diferenças entre os sistemas de atividades gerenciais, como fizemos aqui. É interessante observar que pesquisadores que examinaram outros aspectos chegaram

\section{Gerentes e pequenos empresários buscam}

\section{atingir metas e objetivos a partir dos recursos disponíveis, dentro de uma estrutura predefinida ou copiada.}

Alguns operadores são bastante habilitados em suas áreas - ou negócios - e controlam os resultados rigorosamente. Algumas vezes, eles irão trabalhar a qualidade dos gastos ou a lucratividade. Muitos tipos diferentes de pequenos negócios existem, com muitos níveis diferentes de habilidade operacional e também muitos níveis de qualidade de produto, dependendo do campo. Nossa amostragem continha poucos pequenos negócios cujo gerenciamento requeria alto nível de habilidade técnica ou de engenharia. Por exemplo, a Hytec, uma empresa na região de Montpellier, no sul da França, fabrica equipamentos altamente sofisticados para clientes como a Nasa. Embora na época dos estudos (1990) ela tivesse menos de 50 empregados, o controle de qualidade dos produtos tinha que ser extensivo e impecável. Isso levou à introdução de uma série de controles de custo e de outros tipos. De modo geral, entretanto, a maioria dos pequenos negócios conduzidos por operadores que foram estudados na pesquisa faziam uma monitoração seletiva em vez de um controle rigoroso. A abordagem dos operadores parece ser mais próxima da monitoração feita pelos empreendedores do que do controle mais sistemático feito pelos gerentes. No geral, entretanto, é bem menos extensiva e menos organizada.

\section{DISCUSSÃO E CONCLUSÃO}

A literatura sobre empreendedorismo contém um corpo de trabalho que discute as diferenças entre gerentes e empreendedores (Hartmann, 1959; Gasse, 1978; Scholhammer e Kuriloff, 1979; Bellu, 1988). No entanto, muito pouco se falou sobre as diferenças entre empreendedores e operadores de pequenos negócios (Smith, 1967; Leibenstein, 1978; Julien e Marchesnay, 1987). Pelo que sabemos, ninguém até a conclusões semelhantes às nossas. Taylor e McRae (1990), por exemplo, identificaram mais semelhanças entre empreendedores e gerentes de pequenos negócios do que entre gerentes de pequenos negócios e executivos de corporações. Blais e Toulouse (1991), num estudo comparativo entre 1.338 empreendedores e 1.553 não-empreendedores em sete países, descobriram que os empreendedores tendem a valorizar o empreendedorismo, enquanto os não-empreendedores valorizavam a segurança do emprego. Hoy e Carland (1983) e Carland et al. (1984) demonstraram que apenas uma pequena porcentagem dos negócios são geridos por verdadeiros empreendedores (entre $21 \%$ e $32 \%$ nos Estados Unidos). Na Europa, embora comparações dessa natureza sejam difíceis, nossa amostragem sugere que um número equivalente a $10 \%$ seria provavelmente um tanto generoso. Por exemplo, em 1985, foi necessário mais de um mês de trabalho intensivo para identificar 15 empreendedores de sucesso na Escócia. No mesmo ano, o mesmo processo, na região de língua francesa da Suíça, apresentou somente 10 empreendedores bemsucedidos a partir de uma lista de mais de 400 pequenos negócios.

A pesquisa mostrou que as atividades nos sistemas gerenciais dos empreendedores e dos operadores diferem substancialmente daquelas nos sistemas de executivos de corporações, naquilo em que parecem ser mais orgânicas, embora, no caso de operadores que gerenciam pequenos ou médios negócios, os fluxos operacionais pareçam ser bem mais regulares. A maior diferença entre os sistemas de empreendedores e operadores recai basicamente sobre definições de raiz. Empreendedores têm "sonhos realistas", ou visões, com cuja realização estão comprometidos. Operadores, por outro lado, simplesmente querem dar bom uso às suas habilidades de forma a ganhar a vida. Quase $90 \%$ dos operadores da amostragem trabalhavam em função de um horário razoavelmente definido, como se tivessem um trabalho de responsabilidade em uma grande firma. A empresa ocupa um lugar muito menos importante na vida dos operadores do que dos empreendedores. O processo de empreendedorismo é envolvente e total, tanto para o próprio empreendedor quanto para os co- 
laboradores próximos que eles empregam para ajudar a tornar sua visão realidade. Para os operadores, a sua vida profissional é apenas uma dimensão do seu sistema de vida geral, na qual outros elementos, tais como família, atividades de lazer ou hobbies, são tão ou mais importantes. Essas definições básicas distintas os levam a construir sistemas de atividades gerenciais bem diferentes, que funcionam de modo bem diverso. Empreendedores tendem a iniciar um processo de desenvolvimento, enquanto operadores desempenham operações. As definições de raiz refletem culturas de empreendedorismo e gerenciais bem distintas. Uma grande diferença no tipo de sistema social construído emerge de uma das mais significantes distinções entre empreendedores e operadores: o desenvolvimento de uma visão. Os operadores contratam recursos humanos com base na tarefa a ser realizada e freqüentemente escolhem alguém que já conhecem. Para os empreendedores, no entanto, a visão é uma condição vital básica. Por terem desenvolvido uma visão, tais empreendedores selecionam empregados que poderão progredir com eles ao longo do tempo. Os operadores, por outro lado, sempre reclamam que seus empregados são incompetentes. Não é difícil entender por quê. Os empregados são contratados para uma tarefa específica, mas, com o passar dos anos, as tarefas mudam, e eles não mais têm habilidades para desempenhá-las adequadamente. Em contraste, os empreendedores mantêm seus recursos humanos por anos a fio e expressam alto nível de satisfação com seus colaboradores. O tempo que eles gastam comunicando para onde eles estão indo e o que esperam de seus empregados permite a ambos os lados evoluírem juntos e continuamente se ajustarem uns aos outros. Mais que simplesmente desempenhar tarefas, eles são reunidos em torno de um contrato psicológico no qual o respeito mútuo e a lealdade crescem ao longo do tempo. Eles acabam por se conhecer mutuamente, suas potencialidades, fraquezas e expectativas. Eles continuam aprendendo juntos, dentro de esferas de atividades diferentes, porém complementares. Ao longo do tempo, cada lado se torna gradualmente indispensável para o outro. Eles constroem algo juntos e obtêm prazer com isso. Quando visitamos fábricas ou fizemos entrevistas, não foi raro ver empreendedores e empregados brincando uns com os outros, fazendo piadas ou trocando sorrisos. É interessante observar que os empreendedores parecem passar mais tempo com alguns companheiros de trabalho em particular. Isso depende do prazer que a companhia dessas pessoas lhes proporciona e da relação de apoio e harmonia que eles formam. Há vezes em que novos produtos ou mercados são desenvolvidos como resultado de tais relacionamentos. Esta pesquisa nos levou a refletir sobre tipologias de empreendedorismo. É difícil não comparar nossos empreendedores e operadores com os oportunistas e artífices citados por Smith (1967). Na sua pesquisa, ele observou que o comportamento de empreendedores e operadores lembra em muito o comportamento gerencial dos oportunistas e artífices. Smith identificou um subtipo: o empreendedor inventor (Miner, Smith e Brocker, 1992), que ele achou que não poderia ser classificado em nenhuma categoria. Nossa amostragem de gerentes-proprietários incluía quatro pessoas desse tipo. Eles foram classificados como operadores ou empreendedores de acordo com a maneira como haviam organizado seus sistemas de atividades. Isso poderia ser um caminho interessante para uma pesquisa futura.

Ao apresentar uma pesquisa dessa natureza, com tantos dados, algumas escolhas tiveram que ser feitas. Por exemplo, deixamos de lado deliberadamente qualquer comparação entre atividades gerenciais, processos e sistemas entre países diferentes. Nossos comentários sobre literatura, embora esta fosse examinada com bastante cuidado antes de se começar a pesquisa, também foram limitados.

As diferenças observadas entre empreendedores e operadores também levantam algumas questões. Por exemplo, como cada tipo define o sucesso? Qual é o lugar ocupado pelo negócio nos critérios usados para se definir o sucesso? Quais habilidades são necessárias para se agir como um empreendedor ou operador de pequeno negócio, de acordo com diferentes sistemas de atividades gerenciais? Seria interessante estabelecer um perfil para cada grupo e identificar os critérios mais adequados de seleção e atividades de treinamento. Por exemplo, a grande preocupação com aspectos estratégicos mostrada pelos empreendedores pode ser resultado de habilidades e práticas conceituais que eles vêm desenvolvendo em níveis diferentes. Também seria interessante estabelecer configurações de contingências de recursos humanos que reflitam melhor os respectivos sistemas de cada grupo. Além disso, é necessário um trabalho futuro sobre os próprios sistemas de atividade em geral. Por exemplo, pode ser interessante apresentá-los e compará-los usando outros paradigmas e diagramas metafóricos, tais como teoria de sistemas e abordagem de contingência. Seria, então, possível construir modelos de sistemas de atividades universais para em- 
preendedores e operadores. Devido à complexidade do fenômeno, mais que uma simples abordagem reducionista, uma pesquisa futura poderia concentrar- se na identificação dos indicadores que seriam úteis para os homens e as mulheres que comandam pequenos negócios. $\bigcirc$

\section{REFERÊNCIAS BIBLIOGRÁFICAS}

ANDERSON, R. L., DUNKELBERG, J. S. Managing small business. Minneapolis/St. Paul: West Publishing, 1993.

BELLU, R. R. Entrepreneurs and managers: are they different? In: KIRCHOFF, B. A. et al. (Eds.). Frontiers of entrepreneurship research. s.l.: Babson College, 1988. p.16-30

BLAIS, R. A., TOULOUSE, J. M. Cultural values of entrepreneurs and non-entrepreneurs. In: ANNUAL WORLD CONFERENCE, ICSB (INTERNATIONAL COUNCIL FOR SMALL BUSINESS), 36, June 1991, Vienna. BENSCH, D., MUGLER, J. (Eds.), Proceedings, v.1, 1991. p.144-57.

BROOM, H. H., LONGENECKER, J., MOORE, C. W. SMall business management. 6 . ed. Cincinnati: South Western Publishing, 1983.

CARLAND, J. W. et al. Differentiating entrepreneurs from small business owners: a conceptualization. Academy of Management Review, v.9, n.2, p.354-9, 1984

CLARAN, R., HOFER, C. W., MAHON, J. F. From entrepreneurial to professional management: a set of guidelines. Journal of Small Business Management, v.18, n.1, p.1-10, 1980.

CHECKLAND, P. Systems thinking, systems practice Chichester, NY: Wiley, 1981.

CHURCHILL, N. C., LEWIS, V. L. The five stages of small business growth. Harvard Business Review, p.30-50, May/June 1983a.

CURTIS, D. A. Strategic planning for smaller business. Lexington, Mass., Toronto: Lexington Books, 1983.

D'AMBOISE, G., NKONGOLO, B. Vision stratégique: concept et signification empireque. (Document spécial 92-109), Faculté des Sciences de L'Administration, Université Laval, 1992.

DAVENPORT, T. H. Process innovation: reengineering work through information technology. Boston: Harvard Business School Press, 1993.

DAVIS, E. W., WHYBARK, D. C. Small business inventory management. Production and Inventory Management, v.17, n.3, p.83-95, 1976

EMERSON, H. The twelve principles of efficiency. New York: Engineering Magazine Co., 1912.

FAYOL, H. General and industrial management. London: Pitman, 1949

FILION, L. J. The strategy of successful entrepreneurs in small business: vision, relationships and anticipatory learning. Lancaster, 1988. 2v. Thesis (Ph.D.) - University of Lancaster Great Britain. (UMI 8919064)

Le développement d'une vision: um outil stratégique à maitriser. Gestion: Revue internationale de gestion, v.14, n.3, p.24-34, Sept. 1989a.

The design of your entrepreneurial learning system: identify a vision and assess your relations system. In: CANADIAN CONFERENCE ON ENTREPRENEURIAL STUDIES, 3, 1989. McKIRD, J. G. M. (Ed.). Proceedings... 1989b. p.77-90.
. Vision and relations: elements for an entrepreneurial metamodel. In: ANNUAL BABSON ENTREPRENEURSHIP RESEARCH CONFERENCE, 10, Apr. 1990, Babson College, MA. CHURCHILL, Neil C. et al. (Eds.). Frontiers of entrepreneurship research: Babson College, 1990a. p.57-71.

Les entrepreneurs parlent. Montreal, Qc: Éditions de l'entrepreneur, 1990b.

The nature of small business and its implications for managerial activities. In: SMALL BUSINESS, MARKETING AND SOCIETY CONFERENCE, Oct. 1991a. (Organized by the Institute of Sociology, USSR Academy of Science, Academy of Science of Georgia, Centre for Sociology at Tbilisy, Georgia, USSR)

Vision et relations: clefs du succés de l'enterpreneur. Montreal, Qc: Éditions de l'entrepreneur, 1991b.

The use of SSM as a metamodel elaboration and control approach. Systemist - The Publication of the United Kingdom System Society, v.13, n.4, p.172-8, Nov. 1991c.

Soft system methodology for an entrepreneuria metamodel. In: RODRIGUEZ-DELGADO, R., BANATHY B. (Eds.) International Systems Science Handbook. Madrid, Spain: Systemic Publications, 1993a. p.471-80.

Le développement d'activités de formation en entrepreneuriat: une approche intégrée. In: ANNUAL CONFERENCE OF THE CCSBE (Canadian Council for Small Business and Entrepreneurship), 10, Oct. 1993b, Moncton, N.B.

Ten steps to entrepreneurial teaching, Journal of Small Business and Entrepreneurship Canada, v.11, n.3, p.6878, Apr./June, 1994a.

. Les systèmes de gestion des propriétaires-dirigeants, entrepreneurs et opérateurs de PME regardés à a partir de la métaphore mécanique. In: WORLD CONFERENCE OF THE INTERNATIONAL COUNCIL FOR SMALL BUSINESS (ICSB), 30, 1994b, Strasbourg. OBRECHT, Jean Jacques (Ed.). Les PME/PMI et leur contribution au développement régional et international: proceedings... p.107-18.

. Entrepreneurs and managers: differences and complementarities in the innovation process. In: STIQE 94 INTERNATIONAL CONFERENCE ON LINKING SYSTEMS THINKING, INNOVATION, QUALITY AND ENTREPRENEURSHIP, 2, Dec. 7-9, 1994c, Maribor, Slovenia. In: REBERNIK, M., MULEJ, M. (Eds.). Proceedings, p.71-88.

Empresarios y gerentes: procesos diferentes pero complementarios (Entrepreneurship and management: differing but complementary processes). In: LATIN AMERICAN CONFERENCE ON ENTREPRENEURIAL SPIRIT, 8, Mar. 1995, Cali, Columbia. Centre d'études en administration internationale (CETAI), HEC, Working Paper, n.95-01.

FOWLER, D. Selling and marketing for small business. Business Guide Books, Self-Help Guide for Small Businessmen. London: Sphere Study Aids, 1984.

GAEDEK, R. M., TOOTELIAN, D. H. Small business management 2. ed. Glenview, III: Scott, Foresman, 1985.

GASSE, Y. Characteristics, functions and performance of small firms: owner-managers in two industrial environments. Evanston, 1978. III. Dissertation (Ph.D.) - Northwestern University.

GULICK, L. H., URWICK, L. F. Papers on the Science of Administration. New York: Columbia University Press, 1937.
HAMMER, M., CHAMKY, J. Reengineering the corporation: a manifesto for business revolution. New York: Harper-Collins, 1993.

HARTMANN, H. Managers and entrepreneurs: a usefu distinction. Administrative Science Quarterly, v.3, n.3, p.42951, 1959.

HODGETTS, R. M. Effective small business management. New York: Academy Press, 1982.

HOY, F., CARLAND, J. W. Differentiating between entrepreneurs and small business owners in new venture formation. In: HORNADAY et al. (Eds.). Frontiers of entrepreneurship research. s.l.: Babson College: 1983. p.157-66.

JULIEN, P. A., MARCHESNAY, M. La petite entreprise. Montreal: Vermette, Paris: Vuibert, 1987.

KOONTZ, H., O'DONNELL, C. Management, principes et méthodes de gestion. Montreal, Paris: McGraw-Hill, 1980.

LEIBENSTEIN, H. General X-Efficiency Theory and economic development. London: Oxford University Press, 1978.

MINER, J. B., SMITH, N. R., BROCKER, J. S. Defining the inventor-entrepreneur in the context of established typologies. Journal of Business Venturing, v.7, n.2, p.103-13, 1992.

MINTZBERG, H. The nature of managerial work. Englewood Cliffs, N.J.: Prentice-Hall, 1973.

MORGAN, G. Imagens of organization. Newbury Park, CA Sage Publications, 1986

NADLER, D. A., GERSTEIN, M. S., SHAW, R. B. Organizational architecture. San Francisco: Jossey Bass, 1992.

SCHOLLHAMMER, H., KURILOFF, A. H. Entrepreneurship and small business management. New York: Wiley, 1979.

SMITH, N. R. The entrepreneur and his firm: the relationship between type of men and type of company. Bureau of Business and Economic Research, East Lansing, Michigan: Michigan State University, 1967.

TATE JR., C. E. et al. Successful small business management 3. ed. Plano, Texas: Business Publications. Also Georgetown Ont: Irwin-Dorsey, 1982.

TAYLOR, C. S., McRAE, C. B. Entrepreneurs, small business managers, and large business executives: a comparison of the perceived importance of current business issues. In: CHURCHILL, N. C. et al. (Eds.). Frontiers of entrepreneurship research. s.l.: Babson College, 1990. p.25-6.

TIBBITS, G. E. Small business management: a normative approach. M. S. V. Business Topics, v. 4, p.5-12, Autumn 1979.

VESPER, K. H. (Ed.). Entrepreneurship education. University of Washington, Center for Entrepreneurial Studies, Babson College, 1985.

(Ed.). Entrepreneurship education. Los Angeles, C.A.: The Anderson School, University of California, 1993. 1994

New venture experience. Seattle: Vector Books,

WELCH, J. A., WHITE, J. F. A small business is not a little big business. Harvard Business Review, v. 59, n. 4, p.18-32, July/ Aug. 1981.

NOTAS

1. Para uma revisão mais completa da literatura, ver Filion (1988

2. A discussão sobre a literatura a respeito do conceito de visão foi bastante limitada aqui. Para uma abordagem mais completa,

ver Filion (1991b) e D’Amboise e Nkongolo (1992).

3. Do inglês CEO, Chief Executive Officer. 